\title{
Efficacy and cost-effectiveness of universal pre-operative iron studies in total hip and knee arthroplasty
}

\author{
Viju Daniel Varghese ${ }^{1,2^{*}}$ (D), David Liu', Donald $\mathrm{Ngo}^{3}$ and Suzanne Edwards ${ }^{4}$
}

\begin{abstract}
Background: The prevalence of anaemia in patients planned for total hip and knee arthroplasty is about 20\%. Optimising pre-operative haemoglobin levels by iron supplementation has been shown to decrease transfusion rates, complications and associated morbidity. The need for universal screening with iron studies of all elective arthroplasty patients is not clearly defined at present.
\end{abstract}

Methods: Retrospective review of 2 sequential cohorts of patients undergoing primary hip or knee arthroplasty by a single surgeon at a single centre between January 2013 and December 2017. The first group of patients underwent pre-operative iron studies only if found to be anaemic, with a haemoglobin below $12 \mathrm{~g} / \mathrm{dl}$. From January 2015, all patients irrespective of the presence of anaemia were screened with a complete iron profile before surgery. Patients with a confirmed iron deficiency were administered with intravenous iron prior to surgery. The 2 cohorts were compared with regard to blood transfusion rate post-operatively and cost efficiency for universal screening with iron studies.

Results: There was a net decrease in the allogenic blood transfusion rate from 4.76 to 2.92\% when universal iron studies were introduced but the difference was not statistically significant. Obtaining universal pre-operative iron studies is cost neutral with the price of allogenic blood transfusion in a similar cohort. We also diagnosed 5 patients with occult malignancies.

Conclusions: Universal screening with pre-operative iron studies and iron infusion in elective arthroplasty patients may reduce allogenic blood requirements and is cost neutral. An additional benefit is the potential to diagnose asymptomatic malignancies. Further studies are required to show the true benefit of universal pre-operative iron screening.

Keywords: Iron deficiency anaemia, Iron studies, Blood transfusion, Hip and knee replacement

\footnotetext{
* Correspondence: viju.daniel@gmail.com

Ethical Committee approval was obtained for this study.

${ }^{1}$ Gold Coast Centre for Bone and Joint Surgery, 14 Sixth Avenue, Palm Beach,

Queensland 4221, Australia

${ }^{2}$ Present Address: Department of Orthopaedics, Unit 3, Christian Medical

College, Vellore, Tamil Nadu, India

Full list of author information is available at the end of the article
}

(C) The Author(s). 2021 Open Access This article is licensed under a Creative Commons Attribution 4.0 International License, which permits use, sharing, adaptation, distribution and reproduction in any medium or format, as long as you give appropriate credit to the original author(s) and the source, provide a link to the Creative Commons licence, and indicate if changes were made. The images or other third party material in this article are included in the article's Creative Commons licence, unless indicated otherwise in a credit line to the material. If material is not included in the article's Creative Commons licence and your intended use is not permitted by statutory regulation or exceeds the permitted use, you will need to obtain permission directly from the copyright holder. To view a copy of this licence, visit http://creativecommons.org/licenses/by/4.0/ The Creative Commons Public Domain Dedication waiver (http://creativecommons.org/publicdomain/zero/1.0/) applies to the data made available in this article, unless otherwise stated in a credit line to the data. 


\section{Introduction}

The prevalence of anaemia among patients undergoing elective total knee (TKA) and hip arthroplasty (THA) has been demonstrated to be significant, ranging between 19 and 44\%, and increases with age [1-3]. One of the major risk factors for requiring allogenic blood posttotal joint replacement is pre-operative anaemia. Allogenic blood transfusion has been associated with increased post-operative infection rates, length of hospital stay and mortality and morbidity [3]. Pre-operative detection, evaluation and correction of anaemia reduces the need for allogenic blood and the incidence of complications [4]. The fundamental aim of blood management in THA and TKA is to avoid allogenic blood.

Iron deficiency is one of the leading causes of anaemia, accounting for one-third of anaemia cases [5]. However, symptomatic iron deficiency can occur independent of anaemia. Iron deficiency on its own can cause lethargy, may impair pre-operative haemoglobin $(\mathrm{Hb})$ optimisation and delay post-op $\mathrm{Hb}$ recovery and is associated with increased post-operative fatigue and hospital stay $[6,7]$. In a study of 715 elective orthopaedic patients, $18 \%$ of patients were found to be iron deficient in the absence of anaemia [8]. Over half of the body's iron is stored in $\mathrm{Hb}$, while approximately another $25 \%$ is stored intracellularly as ferrous bound to ferritin protein. These two biochemical markers are important indicators for patient recovery in the post-operative period as they reflect the iron levels in the body. The function of ferritin is to replenish iron stores for heme synthesis [9].

Contemporary practice in THA and TKA is to optimise red cell count in the peri-operative period using a variety of methods. These include iron supplementation, erythropoietin and cell salvage re-infusion [10]. Parenteral iron has been shown to be effective by avoiding oral compliance issues and increases $\mathrm{Hb}$ levels within 3 weeks. There is however a paucity of evidence available regarding the use of screening iron studies and intravenous iron infusion pre-operatively with its impact on rates of allogenic blood transfusion in elective orthopaedic surgery [11].

We have been utilising a blood conservation strategy algorithm at our institution, which includes preoperative iron studies in all patients planned for elective THA and TKA surgery from January 2015 [10]. Patients with iron deficiency (serum iron $<5 \mu \mathrm{mol} / \mathrm{l}$ and/or serum ferritin < $100 \mu \mathrm{g} / \mathrm{l}$ and TSAT $<20 \%$ ) were treated with an intravenous iron infusion pre-operatively, irrespective of pre-operative $\mathrm{Hb}$ level. The primary aim of this study is to assess whether our protocol of performing universal iron studies on all patients planned for elective joint replacement surgery helped in decreasing transfusion rates. The secondary aim is to assess the costeffectiveness of pre-operative iron studies in elective THA and TKA.
The study hypothesis is that routine pre-operative iron studies in patients undergoing elective THA and TKA are effective in reducing allogenic transfusion rate and is cost effective.

\section{Methods \\ Study design}

A retrospective review of 2 sequential cohorts of patients who underwent primary THA or TKA under a single surgeon between January 2013 and December 2017 was performed. Universal screening for iron deficiency of all patients irrespective of $\mathrm{Hb}$ level was introduced as part of the pre-operative protocol from January 2015. Patients were considered to be iron deficient if they had a serum iron $<5 \mu \mathrm{mol} / \mathrm{l}$ and/or serum ferritin $<100 \mu \mathrm{g} / \mathrm{l}$ and TSAT $<20 \%$ and were treated with an intravenous iron infusion pre-operatively, irrespective of preoperative $\mathrm{Hb}$ level. Prior to this, only patients found to be anaemic, defined as $\mathrm{Hb}$ level less than $12 \mathrm{~g} / \mathrm{dl}$, were investigated with iron studies and this formed the comparator control group for the study. Between the 2 sequential groups of patients, no other change in patient management or surgical technique was introduced and the surgical time was comparable. Data was collected by review of the hospital records and surgeon's electronic patient files. Ethics approval for the study was obtained by the hospital Research and Ethics Committee.

Demographics of the two study populations are shown in Table 1. The iron studies comprised serum iron, serum ferritin, serum transferrin, serum total iron binding capacity (TIBC) and serum transferrin saturation (TSAT). Patients with studies indicating iron deficiency were referred to a haematologist, who investigated the cause and administered intravenous iron infusion as appropriate pre-surgery. Iron transfusions comprised a single dose of 500-1000mg intravenous ferritin carboxy maltose, administered in a day stay unit, given a minimum 4 weeks before surgery. The primary outcome measure of the study is the blood transfusion rate between the 2 cohorts. Secondary outcome measures such as pre- and post-operative $\mathrm{Hb}$ levels, per-operative blood loss and rates of iron transfusion were also collected. Data in the universal iron screening cohort, regarding patients who were diagnosed to have incidental malignancies on further investigation, was also collected.

All THA were performed through an anterolateral approach in the lateral position. Uncemented acetabular and femoral components were used, with no drain. All TKA were performed using computer navigation without a tourniquet, using cemented components and routine patella resurfacing. A subcutaneous suction drains outside the joint cavity was used in TKA, with the drain removed within $24 \mathrm{~h}$ after surgery. Intra-operative cell salvage was used in all cases with autologous re-infusion 
Table 1 Comparison of cohorts pre- and post-universal screening

\begin{tabular}{llll}
\hline & $\mathbf{2 0 1 3 - 2 0 1 5}$ (pre-universal screening group) & $\mathbf{2 0 1 5 - 2 0 1 7}$ (universal screening group) & $\boldsymbol{P}$-value \\
\hline Number & 420 & 514 \\
Age, mean (SD) & $71.1(9.26)$ & $71.7(9.51)$ & 0.3324 \\
Gender (M:F) & $200: 220$ & $239: 275$ & 0.9805 \\
Side (right:left) & $195: 225$ & $271: 243$ & 0.0484 \\
THA:TKA & $220: 200$ & $296: 218$ & 0.9151 \\
BMl, mean (SD) & $30.12(5.60)$ & $29.56(5.67)$ & 0.1317 \\
Haemoglobin (pre-op), mean (SD) & $134.97 \mathrm{gm} / \mathrm{dl}(12.33)$ & $138.33 \mathrm{gm} / \mathrm{dl}(12.91)$ & 0.0001 \\
Iron deficiency anaemia & $105(25 \%)$ & $180(35 \%)$ & 0.7829 \\
Iron infusion rate & $21(5 \%)$ & $71(13.8 \%)$ & $<0.0001$ \\
Blood transfusion rate & $20(4.8 \%)$ & $15(2.9 \%)$ & 0.0886 \\
\hline
\end{tabular}

if sufficient blood was salvaged. After implantation of components, topical tranexamic acid (3g diluted in 20 $\mathrm{ml} \mathrm{N} /$ saline) was instilled for $5 \mathrm{~min}$ to the surgical site prior to final lavage and closure, followed by $1 \mathrm{~g}$ orally at 3 and $6 \mathrm{~h}$ post-operatively.

Patients were ambulated on the day of surgery. Venous thromboembolism prophylaxis comprised of enoxaparin $40 \mathrm{mg}$ daily commenced $4 \mathrm{~h}$ post-operatively until discharge from hospital. Patients were discharged on aspirin for 6 weeks post-operatively. For patients on warfarin pre-operatively, this was continued during the peri-operative period. Warfarin dose was adjusted leading to surgery, aiming for an international normalisation ratio (INR) of 2 on the day of surgery. The warfarin was restarted the night of surgery, with bridging enoxaparin if the INR fell below 2 .

Data collected included demographics, body mass index (BMI), pre-operative haemoglobin (early $\mathrm{Hb}$ ), iron parameters (serum iron, total iron binding capacity, serum transferrin and serum ferritin), haemoglobin postiron transfusion (late $\mathrm{Hb}$ ) and post-operatively (post-op $\mathrm{Hb}$ ), peri-operative blood loss, type of anaesthesia, ASA grade and type of anticoagulation, total blood loss, blood collected by cell salvage and $\mathrm{Hb}$ change between preoperative and day 2 post-operative. Anaemia in our study is defined as $\mathrm{Hb}$ less than $13 \mathrm{~g} / \mathrm{dl}$ in males and less than $12 \mathrm{~g} / \mathrm{dl}$ in females. The transfusion trigger postoperatively was $\mathrm{Hb}$ less than $8 \mathrm{~g} / \mathrm{dl}$ or symptomatic anaemia with $\mathrm{Hb}$ less than $10 \mathrm{~g} / \mathrm{dl}$ and co-existing comorbidities

\section{Statistical methods}

Descriptive statistics for iron variables were presented for all data and by iron transfusion (performed or not performed), depending on the distribution of the data with mean and standard deviation presented for normally distributed variables. Independent $t$-tests were performed to compare continuous iron variables between the two cohorts.
Bivariate binary logistic regressions were performed for the outcome: blood transfusion versus demographic and blood-related predictors. A multivariable model was performed including previous iron transfusion and variables with $P$ value $<0.2$ on bivariate regression.

Bivariate linear regressions were performed for the outcomes: blood loss, RBC collected and HB drop (in separate models) versus demographic and blood-related predictors. A multivariable model was performed including previous iron transfusion and variables with $P$ value $<0.2$ on bivariate regression. Assumptions of a linear model were checked by inspection of histograms and scatter plots of residuals and predicted values.

A cross tabulation was performed for iron deficiency anaemia versus general anaemia, with an associated chisquare $P$ value.

\section{Results}

Nine hundred and thirty-four patients from 2013 to 2017 were included in the study. There were 420 patients in the group prior to routine iron studies (control group) and 514 in the cohort who underwent routine iron deficiency screening (treatment group). The overall blood transfusion rate in the control group was 20/420 (4.8\%), and in the treatment group, it was $15 / 514$ (2.9\%) with 5 following THA and 10 following TKA. Table 1 shows the demographics, iron deficiency anaemia rates, iron transfusion and blood transfusion rates between the 2 cohorts. There were no major/minor side effects following the iron transfusion. There was an increase in the average $\mathrm{Hb}$ levels of $0.34 \mathrm{~g} / \mathrm{dl}$ because of the universal screening protocol which was statistically significant $(P<0.0001)$. Though there was a reduction in blood transfusion rates, this was not statistically significant (chi-square $P$ value $=0.0980$ ).

In the 514 patients in the treatment group, 9.2\% were detected to have anaemia of which $30 \%$ were iron deficient. Among the treatment cohort with normal $\mathrm{Hb}$, $34.6 \%$ were found to be iron deficient (Table 2). Iron 
Table 2 Prevalence of anaemia and iron deficiency in joint replacement patients

\begin{tabular}{lllll}
\hline & Iron deficiency & Iron deficiency & Total & $\boldsymbol{P}$ value \\
\hline Anaemia & Yes & No & & 0.5990 \\
Yes & 12 & 27 & $39(9.24 \%)$ & \\
No & 134 & 249 & $383(90.76 \%)$ & \\
Total & $146(35 \%)$ & $276(65 \%)$ & 422 & \\
\hline
\end{tabular}

infusions were administered to 71 of $514(13.8 \%)$ patients, with $14.4 \%$ in THA and $13.5 \%$ in TKA.

Tables 3 and 5 outline the distribution of iron indices, early, late and post-operative haemoglobin rates among the hip and knee replacement groups, respectively, and in those patients, who had iron infusion as opposed to those who did not. These results show that there was a significant improvement in the $\mathrm{Hb}$ levels of around $0.3 \mathrm{~g} /$ $\mathrm{dl}$ following the infusion protocol (Tables 4 and 5). The decrease in the $\mathrm{Hb}$ levels post-operatively was similar in the iron transfusion group and non-iron transfusion group. Tables 4 and 6 show comparable demographics for age, BMI and blood loss for both hip and knee cohorts.

Iron infusions were found to be predictive for blood transfusions among TKR patients but not among THR patients (Tables 7 and 8). Low pre-operative Hb was also strongly predictive of blood transfusion rates. Other factors that were positively associated with increased perioperative blood loss and lower post-op $\mathrm{Hb}$ included general anaesthesia, use of warfarin and rivaroxaban as anticoagulants and female gender (Tables 7 and 8).

Among our elective THA and TKA cohorts, we diagnosed 10 patients, following further evaluation of their iron deficiency with underlying gastric causes or malignant disease which were subsequently treated prior to joint arthroplasty surgery. These are listed in Table 9.
Table 4 TKA data: descriptive statistics of demographics

\begin{tabular}{lll}
\hline Variable & Mean & Standard deviation \\
\hline Current age & 72.40 & 8.47 \\
BMl & 30.20 & 5.78 \\
Blood loss & 331.51 & 144.63 \\
RBC collected & 176.82 & 98.54 \\
Hb drop & 2.65 & 0.84 \\
\hline
\end{tabular}

For cost-effectiveness of routine pre-operative iron studies, we calculated the numbers needed to treat (NNT) of our cohort as 49.06. This is derived from the formula, NNT $=1$ /incidence in the control group - incidence in the treated group.

For iron infusion: NNT $=71 / 514 \times 49.06=6.8$

Cost for iron infusion: $6.8 \times \$ 135$ (per iron infusion) $=$ \$ 918 (\$ = Australian dollar/AUD)

For iron studies: NNT $=433 / 514 \times 49.06=41.33$

Cost for iron studies: $41.33 \times \$ 30$ (per iron study) $=$ $\$ 1240$.

Total costs for iron protocol $=$ iron infusion costs + iron studies costs $(\$ 918+\$ 1240)=\$ 2158$

For blood transfusion: $(2 \times 15 / 512) \times 49.06=2.86$ units (each patient had 2 units of blood)

Costs for blood transfusion: $2.86 \times \$ 700$ (per blood unit) $=\$ 2004$

Hence, our universal iron screening and iron infusion protocol are cost neutral with the expense of allogenic blood transfusion ( $\$ 2158$ vs $\$ 2004)$ in this patient cohort.

\section{Discussion}

Universal screening with pre-operative iron studies and iron infusion in elective THA and TKA patients in our study decreased allogenic transfusion rates postoperatively but was not statistically significant. We believe part of the reason why the allogenic transfusion

Table 3 Descriptive statistics for iron variables comparing the iron transfusion group versus the non-iron transfusion group. TKA total knee arthroplasty

\begin{tabular}{|c|c|c|c|c|}
\hline Iron variable & $\begin{array}{l}\text { All data (mean (SD)) } \\
N=296\end{array}$ & $\begin{array}{l}\text { Iron transfusion } \\
\text { (mean (SD)) } N=38\end{array}$ & $\begin{array}{l}\text { No iron infusion } \\
\text { (mean (SD)) } N=258\end{array}$ & $\begin{array}{l}\text { Independent } \\
T \text {-test } P \text { value }\end{array}$ \\
\hline S iron $(5-30 \mu \mathrm{mol} / \mathrm{l})$ & $15.5(5.1)$ & $11.9(4.1)$ & $16.1(5.0)$ & $<0.0001$ \\
\hline Transferrin (1.9-3.1g/l) & $2.5(0.4)$ & $2.8(0.4)$ & $2.5(0.3)$ & 0.0013 \\
\hline TIBC (47-77 $\mu \mathrm{mol} / \mathrm{l})$ & $62.8(8.9)$ & $69.0(10.8)$ & $61.9(8.2)$ & 0.0015 \\
\hline Tran satrn (20-45\%) & $25.7(10.7)$ & $18.1(6.4)$ & $26.9(10.7)$ & $<0.0001$ \\
\hline Ferritin $(30-300 \mu \mathrm{g} / \mathrm{l})$ & $176.1(170.3)$ & $51.0(30.4)$ & $196.0(175.0)$ & $<0.0001$ \\
\hline Early $\mathrm{Hb}(\mathrm{g} / \mathrm{dl})$ & $138.81(11.63)$ & $130.29(12.22)$ & 140.18 (10.95) & $<0.0001$ \\
\hline Late $\mathrm{Hb}(\mathrm{g} / \mathrm{dl})$ & 138.35 (12.04) & $132.25(13.01)$ & $139.22(11.67)$ & 0.0011 \\
\hline Post-op Hb (g/dl) & $112.18(13.38)$ & $105.41(14.44)$ & $113.22(12.93)$ & 0.0009 \\
\hline Intra-operative blood salvage rate & $47.6 \%$ & $45 \%$ & $52 \%$ & $0.4211^{*}$ \\
\hline
\end{tabular}

*Chi-square test $P$ value 
Table 5 Descriptive statistics for iron variables comparing the iron transfusion group versus the non-iron transfusion group. THA total hip arthroplasty

\begin{tabular}{|c|c|c|c|c|}
\hline Iron variable & $\begin{array}{l}\text { All data (mean }(\mathrm{SD})) \\
N=216\end{array}$ & $\begin{array}{l}\text { Iron transfusion } \\
\text { (mean (SD)) } N=33\end{array}$ & $\begin{array}{l}\text { No iron infusion } \\
\text { (mean (SD)) } N=183\end{array}$ & $\begin{array}{l}\text { Independent } \\
T \text {-test } P \text { value }\end{array}$ \\
\hline S iron $(5-30 \mu \mathrm{mol} / \mathrm{l})$ & $15.4(5.2)$ & $13.1(4.7)$ & $15.9(5.1)$ & 0.0067 \\
\hline Transferrin (1.9-3.1g/l) & $2.5(0.4)$ & $2.7(0.3)$ & $2.4(0.30)$ & $<0.0001$ \\
\hline TIBC (47-77 $\mu \mathrm{mol} / \mathrm{l})$ & $62.0(8.9)$ & $68.3(8.0)$ & $60.7(8.5)$ & $<0.0001$ \\
\hline Tran satrn (20-45\%) & $25.6(9.3)$ & $19.8(8.6)$ & $26.8(9.0)$ & 0.0001 \\
\hline Ferritin $(30-300 \mu \mathrm{g} / \mathrm{l})$ & $181.5(149.2)$ & $59.8(54.4)$ & $208.5(150.2)$ & $<0.0001$ \\
\hline Early Hb (g/dl) & $138.95(13.64)$ & $130.39(14.05)$ & $140.64(12.95)$ & 0.0002 \\
\hline Late $\mathrm{Hb}(\mathrm{g} / \mathrm{dl})$ & $138.30(14.05)$ & $134.12(13.23)$ & $139.08(14.10)$ & 0.0626 \\
\hline Post-op Hb (g/dl) & $117.26(13.44)$ & $111.55(11.33)$ & $118.26(13.56)$ & 0.0100 \\
\hline Intra-operative blood salvage rate & $53.2 \%$ & $60 \%$ & $50 \%$ & $0.2912^{*}$ \\
\hline
\end{tabular}

${ }^{*}$ Chi-square test $P$ value

rate was not significant between the 2 groups is our transfusion rate was already very low in the control patients, because of our blood management protocols [12]. Universal screening with iron studies was essentially equivalent cost compared to the savings from reduction in blood transfusion rates. However, we believe preoperative iron screening is still advantageous, as our cost calculation did not factor into account possible complications and increased length of hospital stay which often result from allogenic blood transfusion.

Pre-operative anaemia occurred in 1 out of 10 patients presenting for THA and TKA, of which iron deficiency anaemia was the cause in one-third, which is similar to the results of other studies [13]. Intravenous iron infusion rapidly increases the pre-operative $\mathrm{Hb}$ levels and bypasses the effects of oral compliance and the effect of hepcidin in patients with anaemia of chronic disease. It can help to decrease allogenic transfusion rates, reduce post-op $\mathrm{Hb}$ drop after surgical blood loss and hasten the post-operative recovery rate of $\mathrm{Hb}$. The average decrease in $\mathrm{Hb}$ following THA and TKA is approximately 4g [14]. In our treatment group, we were able to increase the $\mathrm{Hb}$ pre-operatively by average $0.2 \mathrm{~g}$ in TKA and $0.3 \mathrm{~g}$ in the THA cohort. Moreover, the universal screening protocol (2015-2017) significantly increased the average $\mathrm{Hb}$ by a mean of $0.3 \mathrm{~g} / \mathrm{dl}(P<0.0001)$, as compared to the cohort prior to 2015.

One-third of our patients who had normal $\mathrm{Hb}$ had iron deficiency, and this is similar to recent studies [15].

Table 6 THA data: descriptive statistics of demographics

\begin{tabular}{lll}
\hline Variable & Mean & Standard deviation \\
\hline Current age & 68.48 & 9.91 \\
BMI & 28.67 & 5.40 \\
Blood loss & 324.78 & 133.32 \\
RBC collected & 168.72 & 81.91 \\
Hb drop & 2.07 & 0.85 \\
\hline
\end{tabular}

There are 2 important ramifications of this finding. Firstly, iron deficiency on its own, even in the absence of anaemia, can cause lethargy and tiredness. This may then hinder a patient's ability to rehabilitate following surgery [6]. Secondly, iron deficiency is a sign of potential malignancy, especially after the age of 60 . Eight to $15 \%$ of patients with iron deficiency anaemia will have a gastrointestinal (GI) malignancy [16], and colorectal carcinoma presents with iron deficiency anaemia in $50 \%$ of cases [17]. More importantly, patients with iron deficiency alone in the absence of anaemia have been found to have an increased risk of GI malignancy after 2 years [18]. Following the commencement of routine iron screening in our elective THA and TKA patients, we diagnosed 5 malignancies in patients who were otherwise asymptomatic and unaware of their diagnosis. The incidental benefit of diagnosing malignancies early in these patients cannot be discounted, which would not have been possible without universal iron studies which helped us identify these patients and instigate early treatment.

As has been demonstrated in previous studies, gender (female), type of anaesthesia (GA), type of surgery (THR) and low pre-operative $\mathrm{Hb}$ were associated with increased allogenic blood transfusion risk $[19,20]$. Interestingly, we were able to show that pre-operative iron deficiency correlated with blood loss and iron transfusions were a strong prognostic factor for having post-op blood transfusions. This was seen only on bivariate analysis and in the TKA group. The higher blood transfusion rates among patients who underwent iron transfusion could probably be explained by the lower baseline $\mathrm{Hb}$ levels and impaired erythropoiesis. Of the 14 patients transfused, 3 had blood disorders and 4 had multiple comorbidities with anaemia of chronic disease and consequent impaired erythropoiesis, while 4 had ischemic heart disease with stents with a low transfusion trigger. 
Table 7 Factors affecting blood transfusion/blood loss in TKA

\begin{tabular}{|c|c|c|c|}
\hline Total knee arthroplasty data & OR/estimate $(95 \% \mathrm{Cl})$ & Comparison $P$ value & Global $P$ value \\
\hline \multicolumn{4}{|l|}{ Bivariate analysis ${ }^{\mathrm{a}}$} \\
\hline Previous iron transfusion & $13(3,56)$ & & 0.0007 \\
\hline \multicolumn{4}{|c|}{ Multivariable analysis for outcome: blood transfusion ${ }^{a}$} \\
\hline Late pre-operative haemoglobin & $0.80(0.70,0.91)^{\mathrm{a}}$ & & 0.0010 \\
\hline \multicolumn{4}{|c|}{ Multivariable analysis for outcome: blood loss } \\
\hline Type of anaesthesia & & & 0.0111 \\
\hline Spinal/GA vs GA & $-111.4(-185.6,-37.4)$ & 0.0032 & \\
\hline Spinal vs GA & $-71.3(-135.2,-7.5)$ & 0.0286 & \\
\hline Anticoagulants & & & $<.0001$ \\
\hline 0 vs $2^{\mathrm{b}}$ & $-274(-417,-130)$ & 0.0002 & \\
\hline 0 vs $3^{b}$ & $-232.7(-403.0,-62.5)$ & 0.0074 & \\
\hline \multicolumn{4}{|c|}{ Multivariable analysis for outcome: haemoglobin drop } \\
\hline BMI & $-0.02(-0.04,0.0)$ & & 0.0120 \\
\hline Gender (male vs female) & $-0.35(-0.56,-0.15)$ & & 0.0007 \\
\hline Anticoagulants & & & 0.0288 \\
\hline 0 vs $2^{b}$ & $-0.67(-1.26,-0.08)$ & 0.0249 & \\
\hline 1 vs $2^{b}$ & $-1.44(-2.41,-0.48)$ & 0.0034 & \\
\hline Late pre-operative haemoglobin & $0.02(0.01,0.03)$ & & $<.0001$ \\
\hline
\end{tabular}

${ }^{\mathrm{a} B i n a r y}$ logistic regression - odds ratio (95\% confidence interval); modelling the probability that blood transfusion = 'Yes'

${ }^{\mathrm{b}}$ Anti coag ( 0 = Clexane, 1 = aspirin, 2 = warfarin, 3 = all others [rivaroxaban, apixaban])

The weaknesses of this study include the retrospective design and method of data collection via medical record review. There may have been recall bias and inaccurate data entry into the medical record which could have affected the results. Our findings may not be applicable to all regions of the world or all patient ethnicities. Additionally, as the study is a single surgeon series, surgical techniques and protocols may also vary and influence the outcomes and conclusions. Finally, as our allogenic transfusion rate in the control group was already low, the study may be underpowered and hence we were unable to demonstrate statistical significance with allogenic blood transfusion rates. Nevertheless, we believe our findings still highlight several important issues and are

Table 8 Factors affecting blood transfusion/blood loss in THA

\begin{tabular}{|c|c|c|c|}
\hline Total hip arthroplasty data & OR/estimate $(95 \% \mathrm{Cl})$ & Comparison $P$ value & Global $P$ value \\
\hline \multicolumn{4}{|c|}{ Multivariable analysis for outcome: blood transfusion ${ }^{a}$} \\
\hline Late pre-operative haemoglobin & $0.89(0.83,0.95)$ & & 0.0006 \\
\hline \multicolumn{4}{|c|}{ Multivariable analysis for outcome: RBC collected } \\
\hline Iron transfusion, yes vs no & $60.2(22.3,98.1)$ & & 0.0019 \\
\hline \multicolumn{4}{|l|}{ Type of anaesthesia } \\
\hline Spinal vs GA & $-38.7(-68.9,-8.4)$ & & 0.0375 \\
\hline Late pre-operative haemoglobin & $1.46(0.43,2.50)$ & & 0.0056 \\
\hline \multicolumn{4}{|c|}{ Multivariable analysis for outcome: blood loss } \\
\hline Iron transfusion, yes vs no & $85.3(11.7,158.8)$ & & 0.0231 \\
\hline Anticoagulants & & & 0.0496 \\
\hline 0 vs $3^{b}$ & $-162.6(-294.1,-31.1)$ & 0.0153 & \\
\hline 2 vs $3^{b}$ & $-182.4(-363.1,-1.7)$ & 0.0478 & \\
\hline \multicolumn{4}{|c|}{ Multivariable analysis for outcome: $\mathrm{Hb}$ drop } \\
\hline Late pre-operative haemoglobin & $0.02(0.01,0.03)$ & & $<0.0001$ \\
\hline
\end{tabular}

${ }^{a}$ Binary logistic model - odds ratio $(95 \% \mathrm{Cl})$ - modelling the probability that blood transfusion = yes

${ }^{\mathrm{b}}$ Anti coag ( $0=$ Clexane, $1=$ aspirin, 2 = warfarin, $3=$ all others [rivaroxaban, apixaban]) 
Table 9 Pathology diagnosed following evaluation of iron deficiency anaemia

\begin{tabular}{ll}
\hline Gastric erosions/gastric ulcer & 5 \\
Bowel cancer & 3 \\
Haematological cancer & 2 (1 myelodysplastic syndrome, \\
& 1 chronic myeloid leukaemia) \\
\hline
\end{tabular}

relevant to surgeons undertaking THA and TKA, especially so at present, where the focus has shifted to short stay or day care surgery. Correcting pre-operative iron deficiency anaemia, through universal iron studies, may facilitate this. The study is a single surgeon series with a uniform protocol and no change in surgical pathway apart from iron studies between the 2 comparison groups.

Transfusion rates for joint replacements have been reported to be about $18 \%$ for knee and $22 \%$ for hip arthroplasties [21], but can range from 13 to $87 \%$, showing [22] the high variability in clinical practice. Our low allogenic transfusion rates were decreased even further by routine pre-operative iron studies and iron infusion protocol. This could also partly explain why we were not able to show a statistically significant decrease in blood transfusion rates or cost-effectiveness. While Medicare cost of blood transfusion is $\$ 700$ per unit, the cost of maintaining a blood bank and personnel make the actual costs of a unit of blood about 2-5 times more [23]. The true cost of allogenic blood should also factor complications and increased length of hospital stay often associated. Adding hidden costs and having a larger study group might have shown cost-effectiveness with our protocol. A recent systematic review investigating preoperative iron transfusions showed a definite decrease in blood transfusions, length of hospital stay and postoperative infections [24].

\section{Conclusion}

Universal screening with pre-operative iron studies and iron infusion in elective total hip and knee arthroplasty patients may reduce allogenic blood requirements and is cost neutral. An additional benefit is the potential to diagnose asymptomatic malignancies. Further prospective studies with greater power may be required to show the true benefit of universal pre-operative iron screening by factoring into account length of hospital stay, cost of complications and maintenance of the blood bank, and cost benefits of early diagnosis of occult malignancies.

\section{Abbreviations}

TKA: Total knee arthroplasty; THA: Total hip arthroplasty; Hb: Haemoglobin; TIBC: Total iron binding capacity; TSAT: Transferrin saturation; BMl: Body mass index; ASA: American Society of Anesthesiologists; GA: General anaesthesia; NNT: Numbers needed to treat; GI: Gastrointestinal

\author{
Acknowledgements \\ We would like to acknowledge the medical record staff at John Flynn \\ Hospital and the secretarial staff at the Gold Coast Bone and Joint Centre for \\ their help in accessing the data for this study.

\section{Authors' contributions} \\ Authors VDV and DN helped in collecting, tabulating and analysing the data \\ from the hospital records. Author DL was the primary surgeon, who \\ conceptualised the study and developed the protocols and was a major \\ contributor for the study. Author SE was primarily helpful in the statistical \\ analysis. Authors VDV and DL helped in writing and reviewing the \\ manuscript. All authors have contributed to the write up and read and \\ approved the final manuscript.
}

Funding

This study did not receive any funding.

\section{Availability of data and materials}

The datasets used and/or analysed during the current study are available from the corresponding author on request.

\section{Declarations}

Ethics approval and consent to participate

Ethics committee approval for this study was obtained from the Greenslopes Research and Ethics committee (protocol18/44) conducted at the John Flynn hospital, Queensland, Australia, on 30/10/2018.

\section{Consent for publication}

Not applicable

\section{Competing interests}

The authors declare they have no competing interests.

\section{Author details}

${ }^{1}$ Gold Coast Centre for Bone and Joint Surgery, 14 Sixth Avenue, Palm Beach, Queensland 4221, Australia. ${ }^{2}$ Present Address: Department of Orthopaedics, Unit 3, Christian Medical College, Vellore, Tamil Nadu, India. ${ }^{3}$ Gold Coast University Hospital, 1 Hospital Blvd, Southport, QLD 4215, Australia. ${ }^{4}$ Adelaide Health Technology Assessment (AHTA), School of Public Health, University of Adelaide, Adelaide, Australia.

Received: 18 April 2021 Accepted: 21 August 2021

Published online: 27 August 2021

\section{References}

1. Muñoz M, García-Erce JA, Cuenca J, Bisbe E, Naveira E, Awge. On the role of iron therapy for reducing allogeneic blood transfusion in orthopaedic surgery. Blood Transfus. 2012;10(1):8-22. https://doi.org/10.2450/2011. 0061-11.

2. Beris $P$, Muñoz M, García-Erce JA, Thomas D, Maniatis A, Van der Linden P. Perioperative anaemia management: consensus statement on the role of intravenous iron. Br J Anaesth. 2008;100(5):599-604. https://doi.org/10.1093/ bja/aen054.

3. Spahn DR, M.D., F.R.C.A. Anemia and patient blood management in hip and knee surgery: a systematic review of the literature. Anesthesiology. 2010; 113(2):482-95. https://doi.org/10.1097/ALN.0b013e3181e08e97.

4. Abdullah HR, Sim YE, Hao Y, Lin GY, Liew GHC, Lamoureux EL, et al. Association between preoperative anaemia with length of hospital stay among patients undergoing primary total knee arthroplasty in Singapore: a single-centre retrospective study. BMJ Open. 2017;7(6):e016403. https://doi. org/10.1136/bmjopen-2017-016403.

5. Guralnik JM, Eisenstaedt RS, Ferrucci L, Klein HG, Woodman RC. Prevalence of anemia in persons 65 years and older in the United States: evidence for a high rate of unexplained anemia. Blood. 2004;104(8):2263-8. https://doi. org/10.1182/blood-2004-05-1812.

6. Gomez-Ramirez S, Bisbe E, Shander A, Spahn DR, Munoz M. Management of perioperative iron deficiency Anemia. Acta Haematol. 2019;142(1):21-9. https://doi.org/10.1159/000496965. 
7. Arcani R, Suchon P, Venton G, Soubrier C, Gaigne L, Doddoli S, et al. Efficacy of intravenous iron therapy in non-anaemic iron-deficient patients with fatigue. Neth J Med. 2020;78(1):34-6.

8. Bisbe E, Castillo J, Sáez M, Santiveri X, Ruíz A, Muñoz M. Prevalence of preoperative anemia and hematinic deficiencies in patients scheduled for elective major orthopedic surgery. Transfusion Alternatives in Transfusion Medicine. 2008;10(4):166-73. https://doi.org/10.1111/j.1778-42 8X.2008.00118.X.

9. Worwood M. Ferritin in human tissues and serum. Clin Haematol. 1982; 11(2):275-307. https://doi.org/10.1016/S0308-2261(21)00338-6.

10. Liu D, Dan M, Adivi N. Blood Conservation Strategies in Total Hip and Knee Arthroplasty. Reconstr Rev. 2015;4(4):39. https://doi.org/10.15438/rr.4.4.85.

11. Muñoz M, Gómez-Ramírez S, Kozek-Langeneker S, Shander A, Richards T, Pavía J, et al. 'Fit to fly': overcoming barriers to preoperative haemoglobin optimization in surgical patients. Br J Anaesth. 2015;115(1):15-24. https://doi. org/10.1093/bja/aev165.

12. Liu D, Dan M, Martinez Martos S, Beller E. Blood management strategies in total knee arthroplasty. Knee Surg Relat Res. 2016;28(3):179-87. https://doi. org/10.5792/ksrr.2016.28.3.179.

13. Jans O, Nielsen CS, Khan N, Gromov K, Troelsen A, Husted H. Iron deficiency and preoperative anaemia in patients scheduled for elective hip- and knee arthroplasty - an observational study. Vox Sang. 2018;113(3):260-7. https:// doi.org/10.1111/vox.12630

14. Pierson JL, Hannon TJ, Earles DR. A blood-conservation algorithm to reduce blood transfusions after total hip and knee arthroplasty. J Bone Joint Surg A. 2004:86(7):1512-8. https://doi.org/10.2106/00004623-200407000-00022.

15. Munoz M, Laso-Morales MJ, Gomez-Ramirez S, Cadellas M, Nunez-Matas MJ, Garcia-Erce JA. Pre-operative haemoglobin levels and iron status in a large multicentre cohort of patients undergoing major elective surgery. Anaesthesia. 2017;72(7):826-34. https://doi.org/10.1111/anae.13840.

16. Goddard AF, James MW, McIntyre AS, Scott BB. Guidelines for the management of iron deficiency anaemia. Gut. 2011;60(10):1309-16. https:// doi.org/10.1136/gut.2010.228874.

17. Wilson MJ, Dekker JWT, Harlaar JJ, Jeekel J, Schipperus M, Zwaginga JJ. The role of preoperative iron deficiency in colorectal cancer patients: prevalence and treatment. Int J Color Dis. 2017;32(11):1617-24. https://doi.org/10.1007/ s00384-017-2898-1.

18. Ioannou GN, Rockey DC, Bryson CL, Weiss NS. Iron deficiency and gastrointestinal malignancy: a population-based cohort study. Am J Med. 2002;113(4):276-80. https://doi.org/10.1016/S0002-9343(02)01214-7.

19. Klement M, Peres-Da-Silva A, Nickel B, Green C, Wellman S, Attarian D, et al. What should define preoperative anemia in primary THA? Clin Orthop Relat Res. 2017;475(11):2683-91.

20. Yoshihara H, Yoneoka D. Predictors of allogeneic blood transfusion in total hip and knee arthroplasty in the United States, 2000-2009. J Arthroplast. 2014;29(9):1736-40. https://doi.org/10.1016/j.arth.2014.04.026.

21. Hart A, Abou Khalil J, Carli A, Huk O, Zukor D, Antoniou J. Blood transfusion in primary total hip and knee arthroplasty. Incidence, risk factors, and thirtyday complication rates. J Bone Joint Surg Am Vol. 2014;96(23):1945-51. https://doi.org/10.2106/JBJS.N.00077.

22. Shander A, Javidroozi M, Ozawa S, Hare GM. What is really dangerous: anaemia or transfusion? Br J Anaesth. 2011;107(Suppl 1):i41-59. https://doi. org/10.1093/bja/aer350.

23. Farmer SL, Towler SC, Leahy MF, Hofmann A. Drivers for change: Western Australia Patient Blood Management Program (WA PBMP), World Health Assembly (WHA) and Advisory Committee on Blood Safety and Availability (ACBSA). Best Pract Res Clin Anaesthesiol. 2013;27(1):43-58. https://doi.org/1 0.1016/j.bpa.2012.12.007.

24. Shin HW, Park JJ, Kim HJ, You HS, Choi SU, Lee MJ. Efficacy of perioperative intravenous iron therapy for transfusion in orthopedic surgery: a systematic review and meta-analysis. PLoS One. 2019;14(5):e0215427. https://doi.org/1 0.1371/journal.pone.0215427.

\section{Publisher's Note}

Springer Nature remains neutral with regard to jurisdictional claims in published maps and institutional affiliations.

Ready to submit your research? Choose BMC and benefit from:

- fast, convenient online submission

- thorough peer review by experienced researchers in your field

- rapid publication on acceptance

- support for research data, including large and complex data types

- gold Open Access which fosters wider collaboration and increased citations

- maximum visibility for your research: over $100 \mathrm{M}$ website views per year

At $\mathrm{BMC}$, research is always in progress.

Learn more biomedcentral.com/submissions 